\title{
Biodegradation of polyethylene: a brief review
}

\author{
Sunil Ghatge ${ }^{1 \dagger}$, Youri Yang ${ }^{1 \dagger}$, Jae-Hyung Ahn ${ }^{2^{*}}$ and Hor-Gil Hur ${ }^{1 *}$
}

\begin{abstract}
Plastic waste management and recycling became a serious global issue as it affects living beings from all the ecosystems. Researchers investigated biodegradation of polyethylene (PE) by measuring changes in various physicochemical and structural characteristics using techniques like as fourier transform infrared spectroscopy (FTIR), scanning electron microscope (SEM), etc. However, these evidences are not enough to prove the exact biodegradation of PE. In this review, we summarized microbial biodegradation of polyethylene and discussed recent developments for the candidate microbial enzymes and their possible roles in PE degradation. In addition, we conversed the advanced technologies correctly used for measuring PE degradation using isotope-labeled PE to figure out its metabolism into the end products like as ${ }^{13} \mathrm{CO}_{2}$.
\end{abstract}

Keywords: Polyethylene, Biodegradation, Pre-treatment, Moth worms

\section{Introduction}

Researches on various synthetic polymers have been accelerated since DuPont had succeeded in mass production and an exclusive sale of nylon in 1940. Versatile properties of plastics, such as diverse application, convenience, non-degradability, and low price, have led to the replacement of natural materials and common use as household items since 1960 . Worldwide the annual production of non-degradable plastic ranges from 350 million to 400 million tons out of that yearly, 5 to 13 million tons of waste plastic are released into the ocean, which is negatively affecting the ecological environment $[47,80]$. In fact, a survey on the Great Pacific Garbage Patch has estimated 80,000 tons of waste plastics have found in the Pacific latitudes, including Hawaii, with $54 \%$ of the waste coming from North America and Asia [58]. Polyethylene and polypropylene represent about $92 \%$ of the synthetic

\footnotetext{
*Correspondence: hyungz@korea.kr; hghur@gist.ac.kr

${ }^{\dagger}$ Sunil Ghatge and Youri Yang are contributed equally to this work

1 School of Earth Sciences and Environmental Engineering, Gwangju Institute of Science and Technology (GIST), Gwangju 61005, Republic of Korea

${ }^{2}$ Agricultural Microbiology Division, National Institute of Agricultural Sciences, Rural Development Administration, Wanju 55365, Republic of Korea
}

plastics produced, and they are used for production of plastic bags, disposable containers, bottles, packaging materials, etc. [16]. An estimated more than 500 billion to 1 trillion plastic bags used globally disturb the ecosystem and ultimately result into serious environmental issues of recycling these materials from the environment $[4,11,20,46,91,118]$.

The waste plastics that form particulate matter by UV irradiation and weathering increase surface area and mobility and thereby incorporate easily into the food chain, causing fatal injuries to all living organisms [14, 97]. In addition, the small size of suspended plastics causes the reduction of light transmission on the sea surface, photosynthetic efficiency of micro-algae, and the productivity of marine organisms. More seriously, the micro-plastic could act as a carrier to increase the adsorption of hardly decomposable hydrophobic chemicals such as polychlorinated biphenyl (PCB), when it is introduced into the food chain $[23,86]$. The groundwater is also contaminated due to hazardous chemicals from the plastic waste in landfills [72].

Based on the annual production of various plastics such as polyamide $(\mathrm{PA})$, polyethylene $(\mathrm{PE})$, polyethylene terephthalate (PET), polypropylene (PP), polystyrene (PS), polyurethane (PU), and polyvinyl chloride (PVC), PE 
and PP that have been widely used in Korea agriculture, comprise more than $60 \%$ of the total global plastic production and the annual production of PE is 116 million tons [21]. In 2015, 6.7 million tons of plastic resins were used in Korea, meaning that every single Korean consumed every single Korean consumed $132.7 \mathrm{~kg}$ of plastic per year. It represented that Korea is the second largest plastic consumer in the world. From the view on generation of waste plastics, about 10.1 million tons of waste plastic generated in 2016 in Korea, indicating $196 \mathrm{~kg}$ of the waste per person per year (EUROMAP [29]). The amount of waste plastics has been increasing every year in Korea (Fig. 1). According to a survey by ministry of environment in Korea, waste plastics from the agricultural environment were 310,000 tons and among them, 200,000 tons were collected and 170,000 tons were recycled (http://stat.me.go.kr). The non-recycled plastics left in the agricultural environment without any management will be getting worse due to a decrease in international oil prices and increase of plastic waste.

$\mathrm{PE}$ is highly recalcitrant and inert material hence it is very difficult to degrade in the environment even after buried for several years as landfill. A polyethylene sheet showed only partial degradation and negligible weight loss when kept in moist soil for 12-32 years [77]. The recalcitrance of $\mathrm{PE}$ is due to its water insolubility, the hydrophobicity because of presence of linear backbone of carbon atoms, degree of crystallinity, and its high molecular weight $[86,111,114]$. PE such as low density polyethylene (LDPE) and high density polyethylene (HDPE), have been used for biodegradation studies [86, 97] (Fig. 2). LDPE was prepared by the high pressure polymerization of ethylene. The presence of branched chains is responsible for the low density of LDPE. Chemically, LDPE is inert at room temperature, however, it can be gradually attacked by strong oxidizing agents and some solvents, results in softening or swelling. It is intact for short period of time up to $95{ }^{\circ} \mathrm{C}$ and can be durable for longer hours at $80{ }^{\circ} \mathrm{C}$. A degree of crystallinity of LDPE is within the range of $50-60 \%$ which provides several properties to the material such as opacity, tear strength, tensile strength, rigidity and chemical resistance, flexibility even at a low temperature $[12,33]$. There

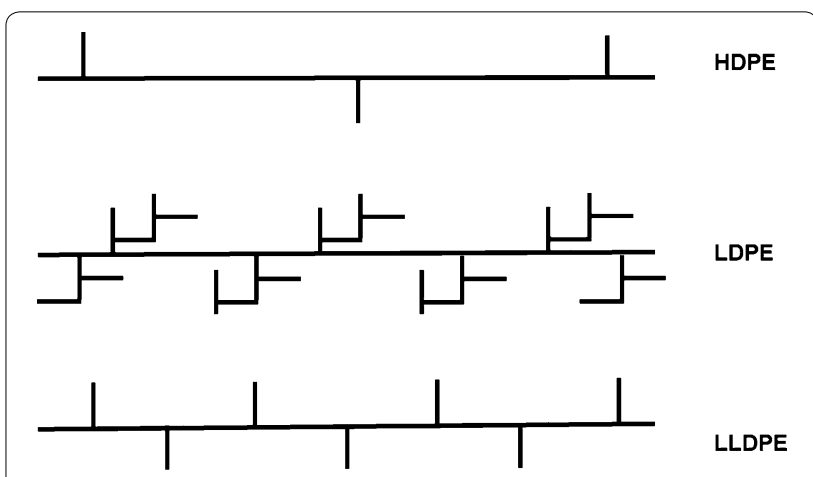

Fig. 2 Structures of different types of polyethylene

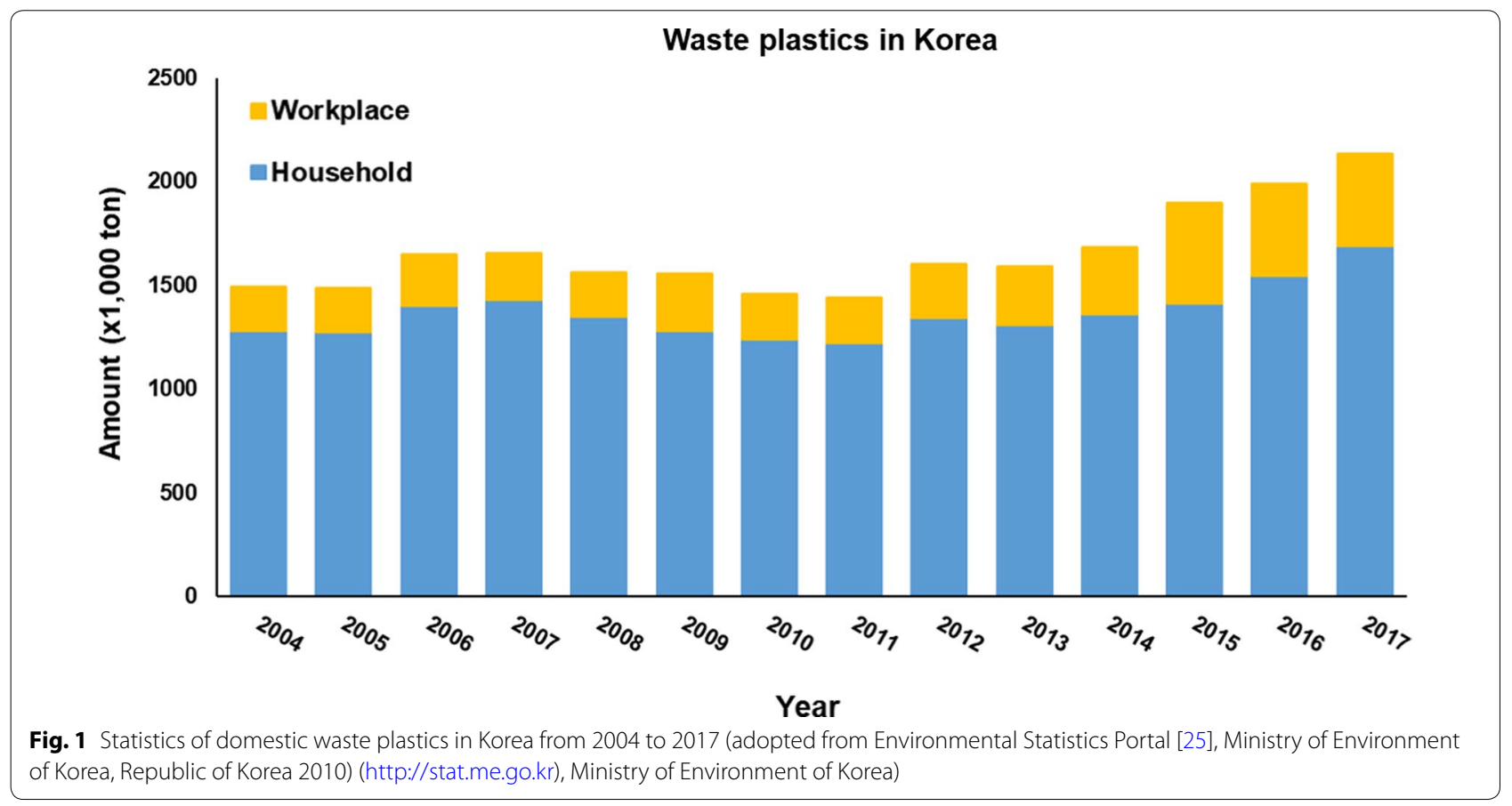


are two different types of LDPE, linear low density polyethylene (LLDPE) and branched low density polyethylene (BLDPE). They show different density, degree of branching and availability of functional groups on the surface. LDPE films are transparent, free from odor and toxicity. They have better ductility, low water vapor permeability, and heat seal ability $[78,109]$. It is widely used for packaging food and non-food items, manufacturing trays and plastic bags. LDPE is utilized for mulching agricultural fields and constructing polyhouse. It is also utilized for coating on paper, textiles, and other plastics [97]. Notably, PE accounts for $97 \%$ of total agricultural waste vinyl and about 200,000 tons of LDPE were consumed, consisting of $64 \%$ of all types of agricultural waste vinyl (Fig. 3) (http://stat.me.go.kr). HDPE is a PE thermoplastic, produced by a catalytic process and having little branching. It has stronger intermolecular forces and greater tensile strength than LDPE. The higher density provides greater stability due to reduced bond length and compact packaging. Due to its hardness, opacity, and durability at higher temperatures (up to $120{ }^{\circ} \mathrm{C}$ ), it is widely used in industrial and day-to-day applications such as production of carry bags, milk jugs, detergent bottles, margarine tubs, garbage containers, water pipes, etc. [8].

The extensive usage of both LDPE and HDPE poses severe environmental threats to the terrestrial and marine ecosystems, as experienced like blockages of $\mathrm{PE}$ in the intestines of fish, birds and marine mammals [10, 99]. In addition, several hundreds of different species from different ecosystems are on the edge of becoming endangered due to the ingestion of this waste $[95,104]$. Inevitable use of PE to increase agricultural productivity in small territory has caused a significant social issue. According to a report by Chinese Academy of Agricultural Sciences in 2014, mulching waste vinyl reduced the movement of essential materials in soil such as air, moisture, and nutrients and the mobility of soil organisms including earthworms [60]. This led to a decrease in soil quality, physiological disorders in plant growth such as seed germination and root growth, which would which would decrease agricultural productivity in the end. Thus, the use and waste treatment for plastics have become a global problem. Therefore, it is of inevitable necessity to minimize PE and other plastics and to develop efficient methods for plastic degradation and recycling.

Extensive research has been carried out for degradation of PE either by physico-chemical or microbial methods or combination of both [14, 86, 97]. Physico-chemical technologies include thermal and UV treatment or combination of both, which reduces the polymer chain size and form oxidized groups such as carboxyl, carbonyl and hydroxyl, on the surface of polymer [19, 44, 57, 68]. These treatments modify the crystallinity and surface morphology of the original polymer and facilitate the polymer biodegradation [59]. Oxidation of PE with nitric acid has been known to promote fragmentation of $\mathrm{PE}$ films followed by microbial degradation [68]. The biodegradation of PE involves use of microbes or microbial communities that modify and consume the polymer as a source of energy leading to changes in its physico-chemical properties such as weight loss, structural deterioration, and eventually carbon fixation as a biomass $[86,97]$. However, the formation of a biofilm by polymer-degrading microorganisms on PE was restricted due to a high degree of hydrophobicity, a low specific surface area and smooth surface topography $[62,86]$. In addition, productive adsorption and catalytic performance of polymerdegrading enzymes have been shown incompatible with a hydrophobic polymer surface $[27,87,88,92]$. Besides, worms of the moth, Galleria mellonella and Plodia interpunctella, have been observed to degrade untreated LDPE $[13,63]$.

In most of these biodegradation studies, PE degradation was determined by measuring weight loss, observing polymer structural changes under SEM, and chemical modifications of functional groups using FTIR [86, 97]. It has been criticized that the weight loss and surface topography changes are probably derived from the degradation of various additives, which often contribute to significant fraction of the PE. Hence, the results from many of these studies need to be cross checked using more advanced physico-chemical, biochemical, and molecular biological technologies [21, 115]. Furthermore, the exact biochemical mechanisms and enzymes involved in PE breakdown are still unknown. From the view on the establishment of waste vinyl management, the researches on finding microorganisms effectively degrading plastics and analyzing their physiology and application are essential.

In this review, we described the effect of pretreatment and additives for enhancing biodegradability of PE and summarized recent studies on biodegradation of PE by various bacteria, fungi, and moth worms along with gut microorganisms from worms. In addition, we discussed candidate microbial enzymes involved in PE biodegradation and various advanced technologies used for evaluating the actual biodegradation of PE.

\section{Pretreatments and effects of additives for enhancing biodegradability of PE Thermo-UV pretreatment}

Thermo-UV pretreatment was used to induce partial photolysis of the PE film and to simulate weathering of $\mathrm{PE}$ that occurs in nature (e.g., PE used for soil mulching or polyhouse cover). PE samples were treated in a QUV accelerated weathering tester developed by QLAB, 


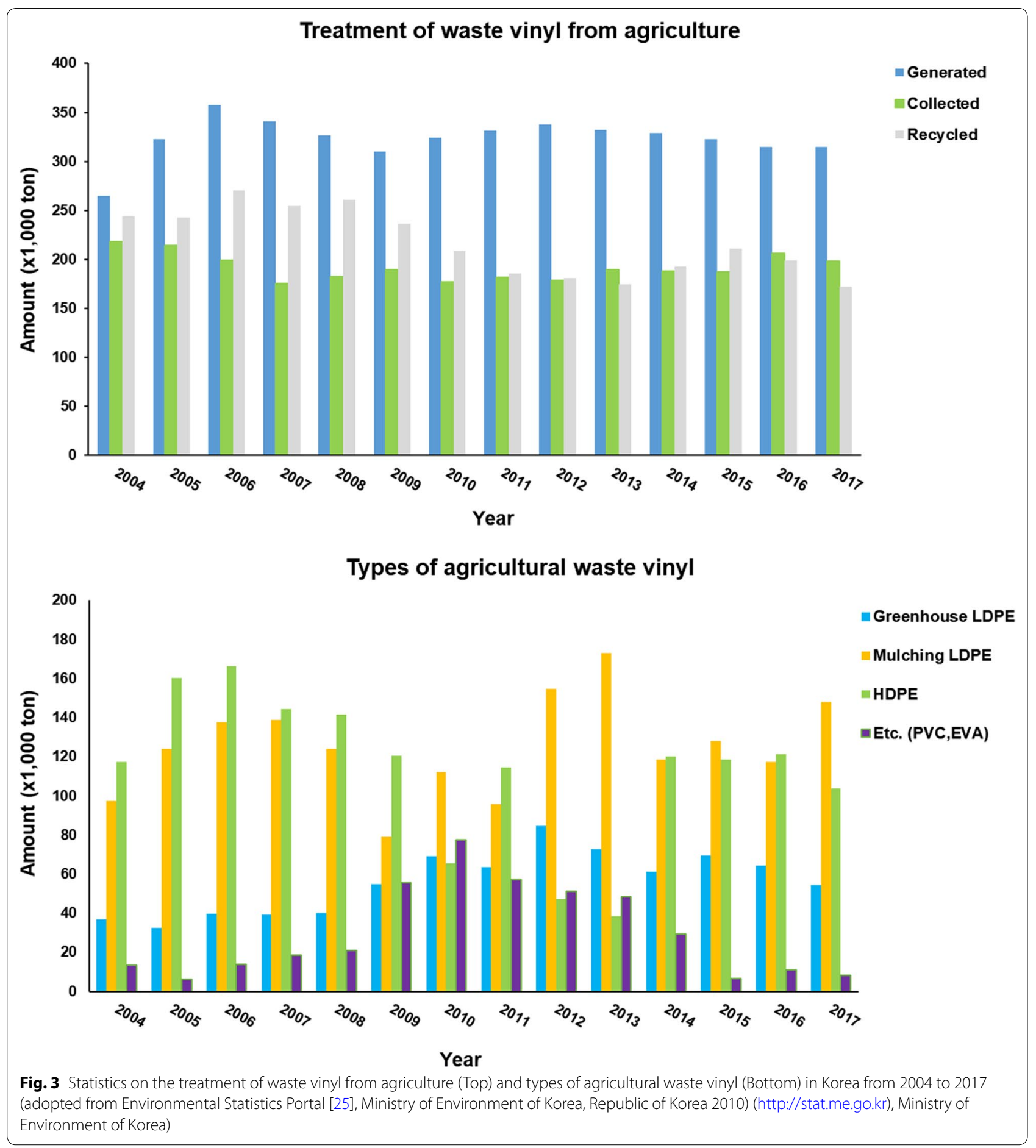

Homestead, FL. Herein, PE was alternatively exposed to cycles of UV and humidity: five cycles per d of UV exposure (four of $4 \mathrm{~h}$ each, one of $3 \mathrm{~h}$ at $70{ }^{\circ} \mathrm{C}$ ) separated by 1 -h intervals $\left(50{ }^{\circ} \mathrm{C}\right)$. The pretreated PE film was tested for biodegradation and biofilm formation by Rhodococcus ruber (C208). FTIR spectra of UV-photooxidized PE incubated with Rhodococcus ruber strain C208 showed that formation of the carbonyl residues on the surface of photooxidized PE plays an important role in initiation of biodegradation [38, 101]. In another study, Bacillus amyloliquefaciens strain isolated from composed plastic was studied for assessing deterioration effect 
of thermo-irradiation pretreatment. Herein LDPE and LLDPE films were exposed to gamma rays followed by thermal treatment at $150{ }^{\circ} \mathrm{C}$ and $90{ }^{\circ} \mathrm{C}$ for $7 \mathrm{~d}$, respectively. Furthermore, LDPE films were additionally exposed to UV irradiation in an oven at $60^{\circ} \mathrm{C}$ for $7 \mathrm{~d}$ [73]. When the pretreated LLDPE was incubated with the isolated bacterium for 40-60 day, the dry weight of LLDPE was slightly decreased by $1.1 \pm 0.3$ to $3.2 \pm 1.3 \%$, with flattening of carbonyl band $\left(1300-1100 \mathrm{~cm}^{-1}\right)$ in the FTIR spectra, indicating a biodeterioration. Electrospray ionization-mass spectrometry (ESI-MS) analysis showed the release of 3-hydroxybutyrate oligomers only in the medium containing pretreated LLDPE and not with native LLDPE. These oligomers disappeared after incubation with Bacillus amyloliquefaciens indicating metabolism of low molecular LLDPE fractions.

Balasubramanian et al. [9] used combination of physical, chemical and biological treatment with Aspergillus terreus MF12 for enhancing HDPE degradation. HDPE film initially heated at $50{ }^{\circ} \mathrm{C}$ for $72 \mathrm{~h}$ followed by exposure to UV (312 nm) and humidity. Secondly, HDPE film was chemically treated by immersing into $\mathrm{KMnO}_{4} / \mathrm{HCl}$ at a concentration of $0.25 / 0.5 \mathrm{~mol} \mathrm{l}^{-1}$ at $45^{\circ} \mathrm{C}$ for $8 \mathrm{~h}$ [32] and $10 \%$ citric acid for $8 \mathrm{~h}$ at $45^{\circ} \mathrm{C}$. The HDPE degradation gradually increased from $9.4 \pm 0.1$ to $20.8 \pm 0.1 \%$ between the physico-chemical and biological treatments, indicating synergism between biotic and abiotic factors for HDPE degradation by A. terreus MF12 [9].

\section{Treatment with pro-oxidants}

All commercial prepared PE films contain a small amount of a stabilizer that prevents oxidation during processing and significantly prolongs its lifetime [15]. Supporting pro-oxidant additives to enhance the photo- and thermooxidation of PE films may lead to radical reactions that result in polymer chain cleavage [54, 55]. Conventional pro-oxidants include transient metal ions such as iron, manganese, titanium, cobalt in the form of stearate. Iron and titanium complexes as a source of radicals initiate photo-oxidation, while manganese and cobalt catalyze peroxidation without light. Study on biodegradation of PE (LDPE) treated with pro-oxidant, manganese stearate followed by UV irradiation and treatment with Aspergillus oryzae resulted in 62 and $51 \%$, decrease in percentage elongation and tensile strength, respectively. Furthermore, FTIR analysis confirmed the formation of more carbonyl and carboxylic groups after treatment with pro-oxidant over UV treated film, which was completely degraded after incubation with $A$. oryzae thus confirming role of pro-oxidants in enhancing $\mathrm{PE}$ biodegradation [52]. Although it is clear that lower molecular weight products were formed by the catalytic action of prooxidants, which were consumed by the microorganisms, however, it is not known how microbes participate in polymer chain cleavage and what kind of enzyme system is involved in this process.

\section{Photo-catalysis using titanium dioxide $\left(\mathrm{TiO}_{2}\right)$}

$\mathrm{TiO}_{2}$ is an ecofriendly photocatalyst that absorbs light in the UV region. Hence, $\mathrm{TiO}_{2}$-incorporated polymer films efficiently absorb UV light. $\mathrm{TiO}_{2}$ mediated photocatalysis involves the absorption of photons of suitable energy leading to the generation of electrons and holes which promote the formation of free radicals, resulting in the oxidation of the polymer, followed by its degradation. Thankam thomas and Sandhyarani et al. (2013) investigated photocatalytic degradation of LDPE incorporated with titania nanoparticles after treatment with solar radiation. The composite PE film showed weight loss of $68 \%$ after exposer to the solar radiation for $200 \mathrm{~h}$ which is a significantly higher compared with a study where the similar rate of weight loss was observed after $400 \mathrm{~h}$ [108, 125]. FTIR and SEM analysis revealed the presence of carbonyl groups and the creation of holes at the interface, respectively indicating the degradation of the LDPE. Another study showed that solar irradiation of a PE film blended with copper phthalocyanine ( $\mathrm{CuPc}$ ) modified $\mathrm{TiO}_{2}\left(\mathrm{TiO}_{2} / \mathrm{CuPc}\right)$ photocatalyst resulted in significant weight loss rate, rough surface texture, higher amount of generated $\mathrm{CO}_{2}$, compared to the original PE film [126]. Surface photovoltage spectroscopy (SPS) analysis suggested that CuPc promoted charge separation of $\mathrm{TiO}_{2}$. Reactive oxygen species generated on the surface of $\mathrm{TiO}_{2}$ or $\mathrm{TiO}_{2} / \mathrm{CuPc}$ particles are responsible for enhanced degradation of PE. Recently, Fa et al. [31] synthesized $\mathrm{TiO}_{2}-\mathrm{FeSt}_{3}$ ferric stearate-polyethylene (TFPE) composite film and studied photo-degradation by treating UV irradiation for $240 \mathrm{~h}$ and/or thermo-degradation at $70{ }^{\circ} \mathrm{C}$ for $30 \mathrm{~d}$. FTIR spectroscopy confirms the formation of carbonyl and hydroxyl group which assist in biodegradation of PE films. The tensile strength and elongation at break of TFPE film reduced to $60 \%$ and $97.7 \%$, respectively [31].

\section{Biodegradation of PE}

The biodegradation of recalcitrant $\mathrm{PE}$ has been investigated by many researchers $[28,40,56,62,98,100,127]$. Still, the complex biodegradation mechanism of PE is not yet fully understood. It is suggested that various abiotic and biotic factors play a vital role in the biodegradation of PE in the environment $[62,100]$. Biodegradation studies have been accomplished either using pure cultures that are able to degrade PE $[2,5,8,34,38,41,54,81,84$, $101,110,113,117,119]$ or using complex microbial communities from various terrestrial (soil from landfill sites, composting) and marine habitats $[1,3,6,18,49,61,71$, 
$74,76,79]$. In addition, it was reported that bioaugmentation with tailored microbial consortia could facilitate the biodegradation of PE [107]. Furthermore, significantly faster biodegradation of PE was observed by waxworms.

\section{Bacterial biodegradation of PE}

More than 20 bacterial genera have been shown to degrade different types of PE. Those include various Gram-negative and Gram-positives species belonging to the genera Pseudomonas, Ralstonia, Stenotrophomonas, Klebsiella, Acinetobactor, etc. and Rhodococcus, Staphylococcus, Streptococcus, Streptomyces, Bacillus, etc. [21, $39,86,97]$.. Most of these bacterial strains possess the ability to deteriorate surface and/or form a biofilm on PE. Table 1 summarizes bacterial strains associated with PE biodegradation. Studies on diverse activities of the genus Pseudomonas have been carried out to investigate their capabilities to degrade and metabolize a variety of synthetic plastics polymers and the by-products. Pseudomonas species have the unique ability to degrade and metabolize the polymers with extracellular oxidative and/ or hydrolytic enzyme activities, which facilitate uptake and degradation of the polymer fragments, and control interaction between biofilms and polymer surfaces [117]. Complete degradation of PE in water was observed after treatment with $P$. fluorescens in presence of surfactant and biosurfactant suggesting their importance in polymer oxidation and biodegradation [5]. Tribedi and Sil [110] showed that the addition of mineral oil to the LDPE degradation medium of Pseudomonas sp. strain AKS2 stimulated the hydrophobic interaction to form biofilms on polymer surfaces and degraded $5 \pm 1 \%$ of the original PE material for $45 \mathrm{~d}$, whereas Tween 80 had an adverse effect to the biofilm formation. A thermophilic bacterium Brevibacillus borstelensis isolated from soil has been reported to utilize BLDPE as the sole carbon and energy source, by which $30 \%$ of the molecular weight of PE film was reduced during an incubation period of $30 \mathrm{~d}$ [41]. [38] isolated a biofilm producing Rhodococcus ruber (C208) strain which degraded PE at a rate of $0.86 \%$ per week. A hydrophobic cell surface (e.g., mycolic acid layer) of this strain may play an important role in biofilm formation on PE surface [38, 101]. Awasthi et al. [7] reported that HDPE after thermal treatment was degraded by Klebsiella pneumoniae. This strain was able to strongly adhere to HDPE surfaces, leading to increasing biofilm thickness with decreasing weight and tensile strength of the HDPE film by $18.4 \%$ and $60 \%$, respectively, in 60 d. Possible biodegradation of an HDPE film exhibits the SEM and atomic force microscopy (AFM) images of subsurface corrosion, cracks, and surface roughness produced by bacteria.

Table 1 Bacterial strains associated with PE degradation

\begin{tabular}{|c|c|c|c|}
\hline Bacterial strain & Substrate & Country of origin & References \\
\hline Streptomyces badius, S. setonii, & starch-PE & USA & {$[81]$} \\
\hline Arthrobacter paraffineus & LDPE, HDPE & Sweden & {$[2]$} \\
\hline Brevibacillus borstelensis & LDPE & Israel & {$[41]$} \\
\hline Nocardia asteroids & LDPE, HDPE & France, Czech Republic & {$[54]$} \\
\hline Rhodococcus rhodochrous & LDPE, HDPE & France, Czech Republic & {$[54]$} \\
\hline Bacillus halodenitrificans & LDPE & India & {$[91]$} \\
\hline Bacillus sphericus & LDPE, HDPE & India & {$[105]$} \\
\hline Arthrobacter sp. & HDPE & India & {$[8]$} \\
\hline Pseudomonas sp. & HDPE & India & {$[8]$} \\
\hline Staphylococcus epidermidis & LDPE & India & {$[17]$} \\
\hline Rhodococcus rhodochrous & LDPE, HDPE, LLDPE & France, Belgium, Italy & {$[34]$} \\
\hline $\begin{array}{l}\text { Arthrobacter viscosus, Acinetobacter baumannii } \\
\text { Bacillus amyloliquefaciens, B. cereus B. circulans, B. mycoides, B. pumilus, B. } \\
\text { thuringienesis, M. luteous, M. lylae }\end{array}$ & LDPE & Poland & {$[74]$} \\
\hline Pseudomonas fluorescens, Paenibacillus macerans, Rahnella aquatilis & LDPE & Poland & {$[74]$} \\
\hline Staphylococcus cohnii & LDPE & Poland & {$[74]$} \\
\hline Staphylococcus xylosus & LDPE & Poland & {$[74]$} \\
\hline Microbacterium paraoxydans & LDPE & India & {$[84]$} \\
\hline Pseudomonas aeruginosa & LDPE & India & {$[84]$} \\
\hline Rhodococcus ruber C208 & LDPE & Israel & {$[93]$} \\
\hline Pseudomonas sp. AKS2 & LDPE & India & {$[110]$} \\
\hline Klebsiella pneumonia & HDPE & India & {$[7]$} \\
\hline
\end{tabular}




\section{Fungal biodegradation of PE}

In addition to bacteria, several fungal genera including Aspergillus, Cladosporium, Fusarium, Penicillium, Phanerochaete have been reported for PE degradation [21, 39, 86, 97]. In general, fungi are thought to be more efficient than bacteria for the degradation of PE because they are capable of attaching to the hydrophobic surface of the polymers [51, 96, 97], producing extracellular enzymes targeting insoluble fibers, and surviving in stressful growth conditions [98]. Table 2 summarizes some fungal strains capable of degrading PE. Weight loss measurement is a commonly used method to analyze biodegradation of PE. For examples, biodegradation of LDPE by A. niger and $A$. japonicas in laboratory conditions have been found to decrease the dry weight by $5.8 \%$ and $11.1 \%$ per month, respectively [82]. Das and Kumar [66] studied microbial deterioration of LDPE by Aspergillus and Fusarium sp. Among them Fusarium sp. FSM-10 and Aspergillus sp. FSM-3 showed maximum weight reduction about $8-9 \%$, while only $5 \%$ weight loss was observed by Aspergillus sp. FSM- 5 after $60 \mathrm{~d}$ of incubation. Usha et al. [112] isolated strains belonging to Aspergillus flavus and $A$. nidulans through enrichment culture showing the clearing zone around their colonies on PE agar plates. Kathiresan [50] isolated PE degrading fungi from mangrove soils. Yamada-Onodera et al. [119] reported degradation of additives free PE by $P$. simplicissimum YK. Esmaeili et al. [26] isolated A. niger from soils of PE wastes landfills using mineral medium with PE powder as a sole carbon source. From SEM and AFM analysis of the PE surface, several strains of Chrysonilia, Aspergillus, and Penicillium species have been isolated using synthetic medium [67]. Among the isolated fungi, $P$. chrysogenum NS10 (KU559907), P. oxalicum NS4 (KU559906) have been evaluated for HDPE and LDPE degradation using the response surface methodology to optimize the growth media for increasing the mycelium weight. The AFM and SEM analysis is widely used to ratify PE degradation by fungal strains leading to biofilm formation and morphological changes on LDPE and HDPE surfaces, including cracks, pits, and undulations [75].

\section{Role of Waxworm and gut microbiome in biodegradation of PE}

Larvae of Galleria mellonella and Plodia interpunctella, have been reported to degrade LDPE without pretreatment $[13,63]$. The worms could soften thin-film PE shopping bags and metabolize them to ethylene glycol. Because there is a structural similarity between beeswax and PE, the biochemical machinery for beeswax metabolism of G. mellonella makes it useful for PE metabolism. About 100 worms of G. mellonella can cause a weight loss of $92 \mathrm{mg}$ from a commercial PE shopping bag within $12 \mathrm{~h}$. [115] criticized that the waxworm research lacked the necessary information to support the claims of the original G. mellonella report. Although the waxworm researches lacked information about the biodegradation mechanism of PE [115], cutting holes on the surface of PE by waxworms and FTIR analysis of degraded PE indicated that PE pieces break down with the carbon-carbon bond cleavage by mechanical force or enzymatic digestion or both. Recently, biodegradation of PE by Enterobacter sp. D1 from the guts of wax moth G. mellonella has been investigated [85]. The authors performed AFM and SEM analysis to show that the strain D1 was able to form colonies around a PE film after14 $\mathrm{d}$ of incubation and disrupted the PE film surface. The treatment of a PE film with the strain D1 has highlighted that the appearance of carbonyl and ether functional groups on the FTIR spectra was concomitant with the release of oxidative cleavage products containing alcohol, ester and acid groups, analyzed by high-performance liquid chromatography-mass spectrometry. This study indicates the involvement of strain D1 in PE degradations. However, it is still unclear that PE is degraded by G. mellonella larvae or by the gut flora. Recently, complete genomic and

Table 2 Fungal strains associated with PE degradation

\begin{tabular}{llll}
\hline Fungal strain & Substrate & Country of origin & References \\
\hline Fusarium redolens & LDPE C14 labelled; UV treated & Sweden & Sweden \\
Verticillium lecanii & LDPE & Turkey & {$[49]$} \\
Phanerochaete chrysosporium & LDPE/starch & Japan & {$[76]$} \\
Penicillum simplicissimum & HDPE UV treated & USA & {$[119]$} \\
Aspergillus niger & Thermal treated LDPE & USA & {$[113]$} \\
Penicillum pinophilum & Powdered LDPE & France, UK & {$[113]$} \\
Cladosporium cladosporioides & Degradable polyethylene green film & Mexico & {$[14]$} \\
Glioclodium virens & Thermal treated LDPE & France, Czech Republic & {$[64]$} \\
Aspergillus flavus & LDPE and HDPE film & {$[54]$} & \\
\hline
\end{tabular}


transcriptomic data of G. mellonella have been used to explore the beeswax and PE metabolism [53]. Notably, the long chain fatty acids from beeswax and PE were detected even in the absence of gut microbiota indicating that the PE metabolism can occur without help of gut microflora.

In another study, two PE-degrading strains, named Bacillus sp. YP1 and Enterobacter asburiae YT1, were isolated from the gut of P. interpunctella larvae [123]. They reduced the hydrophobicity and caused surface disruption of PE film after $28 \mathrm{~d}$ of incubation. After $60 \mathrm{~d}$ of incubation with these strains approximately $10.7 \pm 0.2 \%$ and $6.1 \pm 0.3 \%$ of the PE films $(100 \mathrm{mg})$ were degraded, respectively. These findings demonstrated the importance of gut microbes of moth larvae for PE biodegradation. Yang et al. [120] explored biodegradation of PE and plastic mixtures by yellow mealworms i.e. larvae of Tenebrio molitor. Up to $49.0 \pm 1.4 \%$ of the ingested PE was metabolized to $\mathrm{CO}_{2}$ after incubation with larvae. PE-fed mealworms showed $40.1 \pm 8.5 \%$ reduction in the molecular weights of egested polymer. The gut microbiome study with next generation sequence analysis has shown the abundance of Citrobacter sp. and Kosakonia sp. attached to PE. Both of them are members of the Enterobacteriaceae family which is known to contain PE degrading bacteria's [123]. In addition, Citrobacter sp. (aerobic), and Kosakonia sp. (facultative anaerobic) can utilize oxygen which suggests their involvement in plastic degradation $[37,56,98,111]$. Further studies are required to reveal the mechanism of enzymatic degradation in the guts of mealworms and waxworms, which will facilitate the biodegradation of a variety of plastic materials.

\section{Effects of microbial activity on PE}

The effect of microbial colonization on the surface of PE was studied by monitoring seven different characteristics with respect to the degree of biodegradation of the polymer: functional groups on the surface, hydrophobicity/hydrophilicity, crystallinity, molecular weight distribution, surface topography, mechanical properties, and mass balance (Table 3). The methods used to study these changes have been extensively reviewed in previous studies [86, 97]. Hence we will just briefly discuss each of these 7 characteristics for understanding PE degradation. FTIR spectroscopy is used to study the formation of various functional groups on the surface of PE after the abiotic and biotic oxidation by thermo-UV treatment and microbial degradation. For example, UV and nitric acid treatment to PE led to an increase in absorbance of infrared at $1710-1715 \mathrm{~cm}^{-1}$ (corresponding to carbonyl group) and $1640 \mathrm{~cm}^{-1}$ and $830-880 \mathrm{~cm}^{-1}$ (corresponding to $-\mathrm{C}=\mathrm{C}-$ ), which was then reduced after incubation with microbial consortia [43]. Similarly, Harshvardhan and Jha [42] reported PE biodegradation with an increase in the index of carbonyl bond, the keto carbonyl bond, and the vinyl bond, calculated using FT-IR spectra. These functional groups at the surface of $\mathrm{PE}$ are considered important because oxidized groups cause an increase in the hydrophilicity which in turns results in the efficient attachment of microbes to the PE surface thereby promoting the biodegradation $[2,110]$. The hydrophilicity is usually estimated by measuring the contact angle of the surface with water. A small contact angle with water indicates a high hydrophilicity of the oxidized PE surface [91, 105].

Crystallinity is another important parameter to predict the extent of biodeterioration of the polymer, measured with the help of Differential Scanning Calorimetry (DSC) and FTIR analysis. Generally, the amorphous region is easily accessible and degraded by microorganisms, resulting in an initial increase in crystallinity $[5,44,83]$. After attack (or dwell) in the amorphous regions, microorganisms will start degrading the crystalline region and increase in the proportion of larger crystals $[2,105]$. Size

Table 3 Techniques used for characterization of PE biodegradation

\begin{tabular}{|c|c|c|c|}
\hline Techniques used & Changes in PE & Measured characteristics & References \\
\hline FTIR & Functional groups on the surface & $\begin{array}{l}\text { Keto-carbonyl index (I1715/I1565); Ester-carbonyl index } \\
\quad(|1740 /| 1465) \text {; Vinyl-bound index (I1640/I1465); } \\
\text { Double bound index (1908/I1465); } \\
\text { C-O stretching (I1100) }\end{array}$ & $\begin{array}{l}{[3,6,34,38,41,74} \\
83,93,94,105 \\
113]\end{array}$ \\
\hline Contact angle drop deposition & Hydrophobicity/hydrophilicity & Contac angle with water, Surface energy & {$[6,91,105]$} \\
\hline FTIR/DSC/XRD & Crystallinity & $\begin{array}{l}\text { Crystallinity; Melting temperature; Relative crystallinity; Lamel- } \\
\text { lar thickness }\end{array}$ & {$[2,76]$} \\
\hline HT-SEC/GPC & Molecular weight distribution & Changes in the molecular weight & $\begin{array}{l}{[38] ;} \\
{[41] ;}\end{array}$ \\
\hline SEM/AFM & Surface topography & Molecular weight distribution topography & {$[6,105]$} \\
\hline Instron & Mechanical properties & Tensile strength; Strain energy; \% Elongation and extension & {$[8,14,18]$} \\
\hline Gravimetric $\mathrm{CO}_{2}$ evolution & Consumption of the polymer & Weight loss & {$[34,74,93]$} \\
\hline
\end{tabular}


exclusion chromatography and time of flight mass spectrometry (TOF-MS) analysis gives an idea about molecular weight distribution of the PE after biodegradation. An increase in the average of molecular weight is witnessed after initial degradation of low molecular weight chains $[5,41,81,119]$.

SEM and AFM analyses are commonly employed to investigate surface topography of PE films during biodegradation. Biofilm formation on the surface of the polymers $[14,34,38,54,101,110]$ and penetration of hyphal structures $[44,83,113]$ have been generally observed after incubation with microbes. The structural changes in the formation of pits, holes, and erosions have been observed under SEM indicating surface destruction of $\mathrm{PE}$. Alterations in crystallinity and the average molecular weight as a result of oxidation modify the chemical and mechanical properties of PE. Universal mechanical testing system (UMTS) is preferentially used for studying changes in the mechanical properties of a polymer [74, $79,105]$. However, this method is prone to underestimate the local surface related damage caused by the microorganisms. Microorganisms utilize PE as a sole carbon source and metabolize it to $\mathrm{CO}_{2}$ during respiration and hence measurement of released $\mathrm{CO}_{2}$ can be linked to the amount of polymer consumed. Some studies reported a decrease in the weight of samples measured either by gravimetric measurements $[6,41,74,101,105]$ or by $\mathrm{CO}_{2}$ emissions from the samples $[1,3,49,96]$. Progressive $\mathrm{CO}_{2}$ emissions in the samples are measured to define the total degradation of the polymer along with its rate.

\section{Microbial enzymes involved in PE biodegradation}

The biodegradation of plastics is a complex process involving various abiotic and biotic factors [28, 40, 56, $62,98,100,127]$. The cooperative action of abiotic factors and microorganisms causes fragmentation of the bulk polymer to increase accessible surfaces for biodegradation. Some extracellular enzymes carry out further fragmentation of the polymers [62, 100] (Fig. 4). Several lignin degrading enzymes also participate in the breakdown of the PE thermoplastic [86, 100]. After the initial cleavage of the polymer into oligomers of 10-50 carbon atoms which can be transported into the cell for further metabolism [62, 86]. Biodegradation of PE is restricted by the absence of hydrolysable functional groups in the backbone $[56,86]$. The carbonyl and hydroxyl groups formed from various pretreatment such as thermoUV irradiation or addition of oxidizing agents could be adopted to stimulate biodegradation further [34, 54] a, b). Hence most of the biodegradation studies on PE have been carried out using substrate peroxidation [86].

Microbial enzymes capable of degrading lignin polymer containing oxidizable $\mathrm{C}-\mathrm{C}$ bonds $[35,106]$ have been involved in the biodegradation of PE [56, 86]. These include manganese peroxidase (MnP, EC 1.11.1.13), lignin peroxidases (LiP, EC 1.11.1.14), and laccases (EC 1.10.3.2.) [116]. A copper dependent laccase from $R$. ruber strain $\mathrm{C} 208$ was reported to degrade UV pretreated PE films [93]. Laccase mediated oxidative cleavage of amorphous region of PE films results in formation of easily accessible carbonyl groups and significant decrease in weight of a PE film. Fujisawa et al. [36] showed reduction of the molecular weight of a PE membrane after treatment with laccase from Trametes versicolor in presence of 1-hydroxybenzotriazole as a mediator. Degradation of a high molecular weight PE membrane by $P$. chrysosporium ME-446 and an isolate IZU-154 have been described and MnP from this white-rot fungus was found to be the key enzyme responsible for PE degradation [45]. A partially purified $\mathrm{MnP}$ stimulated degradation of $\mathrm{PE}$ in presence of various surfactants $[24,45]$. The most active $\mathrm{MnP}$ from IZU-154 has been characterized in regard to the oxidation of 2,6-dimethoxyphenol [65] and the degradation of nylon-66 [22]. Enhanced extracellular secretion of laccases and MnP from B. cereus was observed when the strain was incubated with UV-irradiated PE [102]. However, the same PE film treated with a partially purified laccase and a MnP from P. simplicissimum showed negligible weight loss [103]. The LiP activity in the concentrated culture supernatants of lignocellulose degrading Streptomyces species has been reported to responsible for degradation of a heat treated PE [81]. Similarly, up to $70 \%$ degradation of a pre-oxidized high molecular weight PE sample has been reported after 15 d of treatment with P. chrysosporium strain MTCC-787. The extracellular peroxidases play a vital role in the biodegradation of PE by this strain [70].

AlkB family alkane hydroxylases (AH) (EC 1.14.15.3) can degrade hydrocarbon oligomers by terminal or sub-terminal oxidation [89]. Yoon et al. [124] reported action of a recombinant AH from Pseudomonas sp. E4 at $37{ }^{\circ} \mathrm{C}$ for $80 \mathrm{~d}$ converted $20 \%$ of the low molecular weight $\mathrm{PE}$ sample to $\mathrm{CO}_{2}$. Expression of the complete AH system of $P$. aeruginosa strain E7 in E. coli showed $30 \%$ degradation of a PE sample [48]. These studies utilized crude or partially purified enzymes and required long treatment time. Notably, the use of tailored microbial consortia has shown promising degradation of PS and PE compared to the use of single microorganisms $[26,69,91,121]$. Recently, transcriptome analysis of $G$. mellonella fed on beeswax similar to PE showed, upregulation of genes encoding carboxylesterase, lipase, and enzymes related to fatty acid metabolism. However, the detailed mechanisms of these enzymes have not been investigated. 


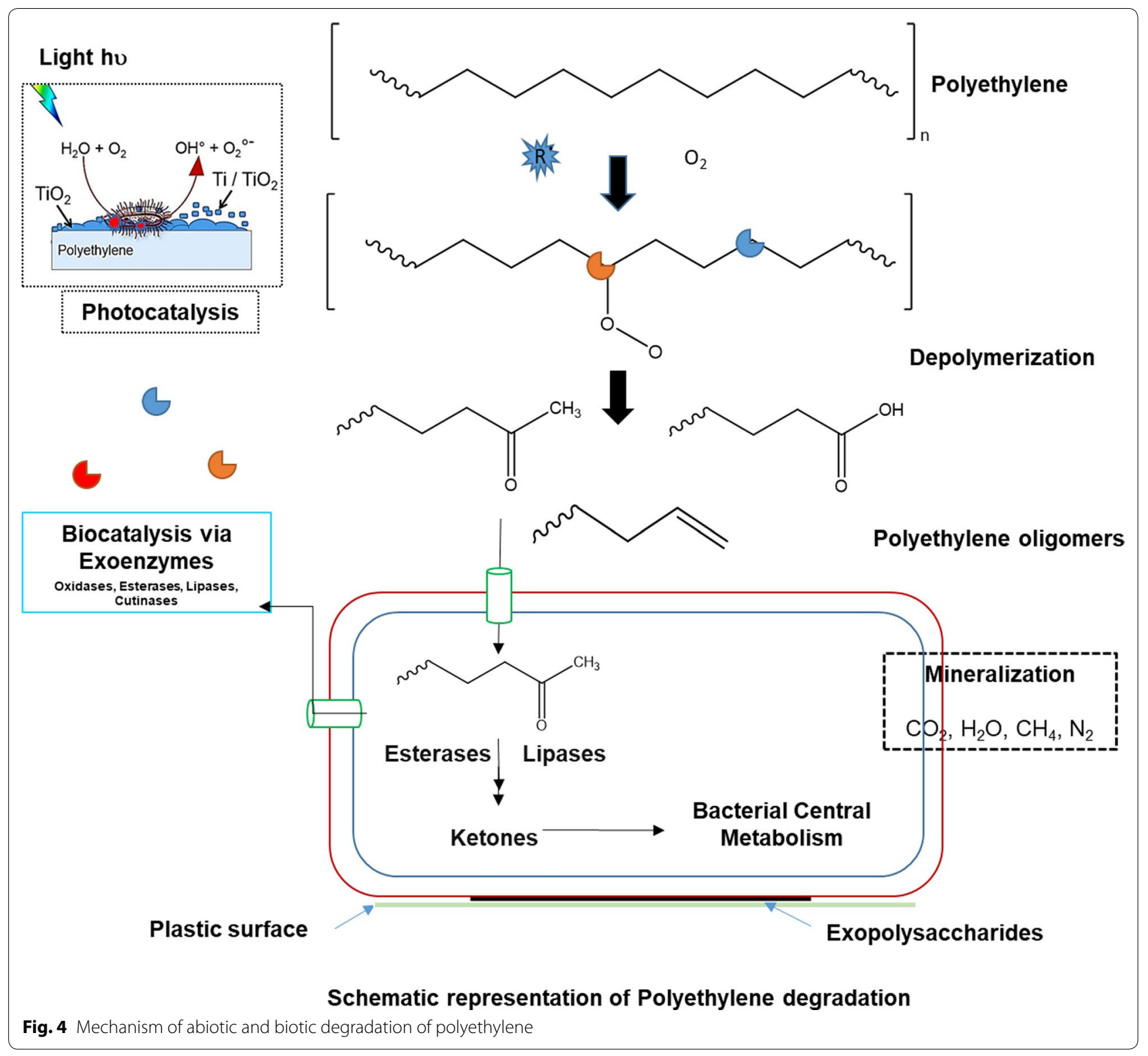

\section{Recent developments in the analytical methods to correctly estimate PE degradation}

Many researchers investigated PE degrading microorganisms using commercially available polymers that possibly contain various chemical additives. The extent of degradation was estimated by calculating weight loss and functional group changes on the surface of polymer by FTIR. However, it is very obscure that the weight loss and surface structure changes result from degradation of additives, which often contribute a major portion of the polymer. Hence, more substantial changes are needed to distinguish the actual degradation of PE and minimizing chances of artifacts originated from the degradation of additives [21, 86, 97]. In this regard, a robust, reliable method has been introduced to assess biodegradability of $\mathrm{PE}$ via the quantification of $\mathrm{CO}_{2}$ using gas chromatography as a result of bacterial degradation and respiration [90]. Herein, the soil bacterium $R$. rhodochrous was grown in a defined aqueous medium with $\mathrm{PE}$ as the only carbon source and the production of $\mathrm{CO}_{2}$ was directly related to the mineralization of the added carbon source via bacterial respiration. At stationary phase, no significant difference in the release of $\mathrm{CO}_{2}$ between cells grown with no carbon source and with LDPE. This suggested that bioavailability of carbon was limited in bacterial growth on LDPE hence showing limited biodegradation. 
Furthermore, the effect of UV pretreatment on biodegradability of LDPE was studied by incubating $R$, rhodochrous with UV pretreated LDPE and native LDPE for $35 \mathrm{~d}$ and released $\mathrm{CO}_{2}$ was measured over the time. The biodegradation of UV treated LDPE was threefold greater than non-treated LDPE. Authors also tested growth of alkanes degrading marine bacteria Alcanivorax borkumensis on LDPE. Negligible difference between $\mathrm{CO}_{2}$ generated by $A$. borkumensis on LDPE and the sample without LDPE indicating that the strain was not able to utilize LDPE.

In another study, 1320 oxidized oligomers from PE films before and after biodegradation with $R$. rhodochrous have been characterized by MS and nuclear magnetic resonance (NMR) spectroscopy [30]. The strain can assimilate $95 \%$ of the soluble oligomers after $240 \mathrm{~d}$. Notably, longer molecules degraded quickly than the smaller ones, suggesting that both extracellular chain cleavage and intracellular $\beta$-oxidation mechanisms play an important role in PE biodegradation. In addition, there are several reports on assessing biodegradability of plastic based on carbon tracing from polymers into $\mathrm{CO}_{2}$ and biomass. Zumestein et al. [128] used ${ }^{13} \mathrm{C}$-labeled polymer poly(butylene adipate-co-terephthalate) (PBAT), and investigated biodegradability in the soil. Various soil microorganisms and filamentous fungi were found to utilize carbon from each monomer unit of PBAT as a carbon and energy source. Biodegradation and mineralization of PS by Tenebrio molitor have been studied using ${ }^{13} \mathrm{C}$-labeled PS $[121,122]$. The analysis of fecula egested from Styrofoam-feeding larvae was performed using ${ }^{13} \mathrm{C}$ cross-polarization/magic angle spinning nuclear magnetic resonance (CP/MAS NMR) spectroscopy, which showed that $47.7 \%$ of the gulped Styrofoam carbon was transformed into $\mathrm{CO}_{2}$ and $49.2 \%$ residue was excreted as fecula with only $0.5 \%$ incorporation into biomass. Thus, tests with labeled PS indicated the degradation of PS into ${ }^{13} \mathrm{CO}_{2}$ and incorporation into lipids [120]. Recently, a mass balance study showed that PE-fed mealworms of Tenebrio molitor converted $49.0 \pm 1.4 \%$ of the ingested PE into $\mathrm{CO}_{2}$ [120]. In addition, $1 \mathrm{H}-\mathrm{NMR}$ data were used to determine the chemical modifications in the residual polymer from the excreta of PE-fed mealworms, in comparison with bran-fed mealworms.

\section{Conclusion and future prospective}

Until now many PE biodegradation studies had investigated changes in physico-chemical properties and structural deterioration using techniques such as FTIR, DSC, XRD, SEM, AFM, etc. Predominantly tested weight loss along with physico-chemical changes are insufficient to prove the real biodegradation of PE. There is a need for providing concrete and reliable evidence for biodegradation of $\mathrm{PE}$ in order to minimize artifacts formed from degradation of additives rather than PE. Hence, upcoming research should be performed using additive-free PE. In addition, ${ }^{13} \mathrm{C}$-polyethylene degradation is proposed to show the formation of ${ }^{13} \mathrm{C}$-labeled metabolites including $\mathrm{CO}_{2}$ emissions, progressively during an incubation period of time. Further investigations on the mechanism of enzymatic degradation will highlight the pathway for an efficient biodegradation of PE at molecular levels.

\section{Abbreviations \\ PE: Polyethylene; FTIR: Fourier transform infrared spectroscopy; SEM: Scan- ning electron microscope; PA: Polyamide; PET: Polyethylene terephthalate; PP: Polypropylene; PS: Polystyrene; PU: Polyurethane; PVC: Polyvinyl chloride; LDPE: Low density polyethylene; HDPE: High density polyethylene; LLDPE: Linear low density polyethylene; BLDPE: Branched low density polyethylene; ESI-MS: Electrospray ionization-Mass spectrometry; $\mathrm{TiO}_{2}$ : Titanium dioxide; CuPc: Copper phthalocyanine; SPS: Surface photovoltage spectroscopy; TFPE: $\mathrm{TiO}_{2}-\mathrm{FeSt}_{3}$ ferric stearate-polyethylene; AFM: Atomic force microscopy; HPLC-MS: High-performance liquid chromatography-mass spectrometry; DSC: Differential Scanning Calorimetry; TOF-MS: Time of flight mass spectrometry; UMTS: Universal mechanical testing system; MnP: Manganese peroxidase; LiP: Lignin peroxidases; AH: Alkane hydroxylases; NMR: Nuclear magnetic resonance; PBAT: Poly(butylene adipate-co-terephthalate); CP/MAS NMR: Cross-polarization/magic angle spinning nuclear magnetic resonance.}

\section{Authors' contributions}

SG and YY written the review and equally contributed for this manuscript; $\mathrm{HGH}$ and JHA revised the manuscript and share the corresponding authorship. All authors read and approved the final manuscript.

\section{Funding}

This study was carried out with the support (PJ01497402) of National Institute of Agricultural Sciences, Rural Development Administration, Republic of Korea.

Availability of data and materials

All data sets presented in this study are included in the published article.

Ethics approval and consent to participate

Not applicable.

Consent for publication

Not applicable.

Competing interests

The authors declare that they have no competing interests.

Received: 19 March 2020 Accepted: 6 May 2020

Published online: 16 May 2020

\section{References}

1. Albertsson AC (1980) The shape of the biodegradation curve for low and high density polyethenes in prolonged series of experiments. Eur Polym J 16:623-630

2. Albertsson AC, Barenstedt C, Karlsson S, Lindberg T (1995) Degradation product pattern and morphology changes as means to differentiate abiotically and biotically aged degradable polyethylene. Polymer 36:3075-3083

3. Albertsson AC, Karlsson S (1990) The influence of biotic and abiotic environments on the degradation of polyethylene. Prog Polym Sci 15:177-192 
4. Andrews GD, Subramanian PM (1992) Emerging technologies in plastics recycling. ACS Symposium Series, 513, American Chemical Society

5. Arkatkar A, Juwarkar AA, Bhaduri S, Uppara PV, Doble M (2010) Growth of Pseudomonas and Bacillus biofilms on pretreated polypropylene surface. Int Biodeterior Biodegradation 64:530-536

6. Artham T, Sudhakar M, Venkatesan R, Madhavan Nair C, Murty KVGK, Doble M (2009) Biofouling and stability of synthetic polymers in seawater. Int Biodeterior Biodegradation 63:884-890

7. Awasthi S, Srivastava P, Singh P, Tiwary D, Mishra PK (2017) Biodegradation of thermally treated high-density polyethylene (HDPE) by Klebsiella pneumoniae $\mathrm{CH} 001$. Biotech 7:332

8. Balasubramanian V, Natarajan K, Hemambika B, Ramesh N, Sumathi CS, Kottaimuthu R, Rajesh Kannan V (2010) High-density polyethylene (HDPE)-degrading potential bacteria from marine ecosystem of Gulf of Mannar India. Lett Appl Microbiol 51:205-211

9. Balasubramanian V, Natarajan K, Rajesh Kannan V, Perumal P (2014) Enhancement of in vitro high-density polyethylene (HDPE) degradation by physical, chemical, and biological treatments. Environ Sci Pollut Res 21:12549-12562

10. Barnes DK, Galgani F, Thompson RC, Barlaz M (2009) Accumulation and fragmentation of plastic debris in global environments. Philos Trans R Soc Lond B Biol Sci 364:1985-1998

11. Bastioli C (2005) Handbook of biodegradable polymers. iSmithers Rapra Publishing, New York

12. Billmeyer FW (1971) Textbook of polymer science, 2nd edn. Wiley, New York

13. Bombelli P, Howe CJ, Bertocchini F (2017) Polyethylene bio-degradation by caterpillars of the wax moth Galleria mellonella. Curr Biol 27:292-293

14. Bonhomme S, Cuer A, Delort A, Lemaire J, Sancelme M, Scott G (2003) Environmental biodegradation of polyethylene. Polym Degrad Stab 81:441-452

15. Briassoulis D, Aristopoulou A, Bonora M, Verlodt I (2004) Degradation characterisation of agricultural low-density polyethylene films. Biosyst Eng 88:131-143. https://doi.org/10.1016/j.biosystemseng.2004.02.010

16. Byuntae L, Anthony LP, Alfred F, Theodore BB (1991) Biodegradation of degradable plastic polyethylene by Phanerocheate and Streptomyces species. Appl Environ Microbiol 3:678-688

17. Chatterjee S, Roy B, Roy D, Banerjee R (2010) Enzyme-mediated biodegradation of heat treated commercial polyethylene by Staphylococcal species. Polym Degrad Stab 95:195-200

18. Chiellini E, Corti A, Swift G (2003) Biodegradation of thermally-oxidized fragmented low-density polyethylenes. Polym Degrad Stab 81:341-351

19. Cornell JH, Kaplan AM, Rogers MR (1984) Biodegradability of photooxidized polyalkylenes. J Appl Polym Sci 29:2581-2597

20. Curlee TR, Das S (1991) Identifying and assessing targets of opportunity for plastics recycling. Resour Conserv Recycl 5:343-363

21. Danso D, Chow J, Streit WR (2019) Plastics: environmental and biotechnological perspectives on microbial degradation. Appl Environ Microbiol 85:1-14

22. Deguchi T, Kitaoka Y, Kakezawa M, Nishida T (1998) Purification and characterization of a nylon-degrading enzyme. Appl Environ Microbiol 64:1366-1371

23. de Souza Machado AA, Kloas W, Zarfl C, Hempel S, Rillig MC (2018) Microplastics as an emerging threat to terrestrial ecosystems. Glob Change Biol 24:1405-1416

24. Ehara K, liyoshi Y, Tsutsumi Y, Nishida T (2000) Polyethylene degradation by manganese peroxidase in the absence of hydrogen peroxide. J Wood Sci 46:180-183

25. Environmental Statistics Portal (http://stat.me.go.kr), Ministry of Environment of Korea, Republic of Korea. 2010

26. Esmaeili A, Pourbabaee AA, Alikhani HA, Shabani F, Esmaeili E (2013) Biodegradation of low-density polyethylene (LDPE) by mixed culture of Lysinibacillus xylanilyticus and Aspergillus niger in soil. PLOS ONE 8:717-720

27. Espino-Rammer L, Ribitsch D, Przylucka A, Marold A, Greimel KJ, Herrero Acero E, Guebitz GM, Kubicek CP, Druzhinina IS (2013) Two novel class II hydrophobins from Trichoderma spp. stimulate enzymatic hydrolysis of poly(ethylene terephthalate) when expressed as fusion proteins. Appl Environ Microbiol 79:4230-4238
28. Eubeler JP, Bernhard M, Knepper TP (2010) Environmental biodegradation of synthetic polymers II. Biodegradation of different polymer groups. TrAC Trend Analy Chem 29:84-100

29. EUROMAP (European Plastics and Rubber Machinery) General Secretariat (2016) Plastics resin production and consumption in 63 countries worldwide (2009-2020). Germany

30. Eyheraguibel B, Traikia M, Fontanella S, Sancelme M, Bonhomme S, Fromageot D, Lemaire J, Lauranson G, Lacoste J, Delort AM (2017) Characterization of oxidized oligomers from polyethylene films by mass spectrometry and NMR spectroscopy before and after biodegradation by a Rhodococcus rhodochrous strain. Chemosphere 184:366-374

31. Fa W, Wang J, Ge S, Chao C (2020) Performance of photo-degradation and thermo-degradation of polyethylene with photo-catalysts and thermo-oxidant additives. Polym Bull 77:1417-1432

32. Favaro SL, Rubira AF, Muniz EC, Radovanovic E (2007) Surface modification of HDPE, PP, and PET films with $\mathrm{KMnO} / \mathrm{HCl}$ solutions. Polym Degrad Stab 92:1219-1226

33. Ferreira LM, Falcão AN, Gil MH (2005) Modification of LDPE molecular structure by gamma irradiation for bio applications. Nucl Instrum Methods B 236:513-520

34. Fontanella S, Bonhomme S, Koutny M, Husarova L, Brusson JM, Courdavault JP, Pitteri S, Samuel G, Pichon G, Lemaire J, Delort A (2010) Comparison of the biodegradability of various polyethylene films containing pro-oxidant additives. Polym Degrad Stab 95:1011-1021

35. Freudenberg K, Neish AC (1968) Constitution and biosynthesis of lignin. Springer-Verlag, Berlin Heidelberg

36. Fujisawa M, Hirai H, Nishida T (2001) Degradation of polyethylene and nylon-66 by the laccase-mediator system. J Polym Environ 9:103-108

37. Gautam R, Bassi SB, Yanful EKY (2007) A review of biodegradation of synthetic plastic and foams. Appl Biochem Biotechnol 141:85-108

38. Gilan I, Hadar Y, Sivan A (2004) Colonization, biofilm formation and biodegradation of polyethylene by a strain of Rhodococcus ruber. Appl Microbiol Biotechnol 65:97-104

39. Glaser JA (2019) Biological Degradation of Polymers in the Environment. Plastic in the Environ, IntechOpen

40. Gu JD (2003) Microbiological deterioration and degradation of synthetic polymeric materials: recent research advances. Int Biodeterior Biodegradation 52:69-91

41. Hadad D, Geresh S, Sivan A (2005) Biodegradation of polyethylene by the thermophilic bacterium Brevibacillus borstelensis. J Appl Microbiol 98:1093-1100

42. Harshvardhan K, Jha B (2013) Biodegradation of low-density polyethylene by marine bacteria from pelagic waters, Arabian Sea, India. Mar Pollut Bull 77:100-106

43. Hasan F, Shah AA, Hameed A, Ahmed S (2007) Synergistic effect of photo and chemical treatment on the rate of biodegradation of low density polyethylene by Fusarium sp. AF4. J Appl Polym Sci 105:1466-1470

44. Huang J, Shetty AS, Wang M (1990) Biodegradable plastics: a review. Adv Polym Technol 10:23-30

45. liyoshi Y, Tsutsumi Y, Nishida T (1998) Polyethylene degradation by lignin-degrading fungi and manganese peroxidase. J Wood Sci 44:222-229

46. Ishiaku US, Pang KW, Lee WS, Mohamad IZA (2002) Mechanical properties and enzymic degradation of thermoplastic and granular sago starch filled polycaprolactone. Eur Polym J 38:393-401

47. Jambeck JR, Geyer R, Wilcox C, Siegler TR, Perryman M, Andrady A, Narayan R, Law KL (2015) Plastic waste inputs from land into the ocean. Science 347:768-771

48. Jeon HJ, Kim MN (2015) Functional analysis of alkane hydroxylase system derived from Pseudomonas aeruginosa E7 for low molecular weight polyethylene biodegradation. Int Biodeterior Biodegradation 103:141-146

49. Karlsson S, Ljungquist O, Albertsson A (1988) Biodegradation of polyethylene and the influence of surfactants. Polym Degrad Stab 21:237-250

50. Kathiresan K (2003) Polythene and plastic-degrading microbes in an Indian mangrove soil. Rev Biol Trop 51:629-633

51. Kershaw MJ, Talbot NJ (1998) Hydrophobins and repellents: proteins with fundamental roles in fungal morphogenesis. Fungal Genet Biol 23:18-33 
52. Konduri MKR, Koteswarareddy G, Rohini Kumar DB, Venkata Reddy B, Lakshmi Narasu M (2011) Effect of pro-oxidants on biodegradation of polyethylene (LDPE) by indigenous fungal isolate, Aspergillus oryzae. J Appl Poly Sci 120:3536-3545

53. Kong HG, Kim HH, Chung JH, Jun JH, Lee S, Kim HM, Jeon S, Park SG, Bhak J, Ryu CM (2019) The Galleria mellonella hologenome supports microbiota-independent metabolism of long-chain hydrocarbon beeswax. Cell Rep 26:2451-2464

54. Koutny M, Lemaire J, Delort AM (2006) Biodegradation of polyethylene films with pro-oxidant additives. Chemosphere 64:1243-1252

55. Koutny M, Sancelme M, Dabin C, Pichon N, Delort A, Lemaire J (2006) Acquired biodegradability of polyethylenes containing pro-oxidant additives. Polym Degrad Stab 91:1495-1503

56. Krueger MC, Harms H, Schlosser D (2015) Prospects for microbiological solutions to environmental pollution with plastics. Appl Microbiol Biotechnol 99:8857-8874

57. Krupp LR, Jewell WJ (1992) Biodegradability of modified plastic films in controlled biological environments. Environ Sci Technol 26:193-198

58. Lebreton L, Slat B, Ferrari F, Sainte-Rose B, Aitken J, Marthouse R, Hajbane S, Cunsolo S, Schwarz A, Levivier A, Noble K, Debeljak P, Maral H, Schoeneich-Argent R, Brambini R, Reisser J (2018) Evidence that the Great Pacific Garbage Patch is rapidly accumulating plastic. Sci Rep 8:4666

59. Lee B, Pometto AL, Fratzke A, Bailey TB (1991) Biodegradation of degradable plastic polyethylene by Phanerochaete and Streptomyces species. Appl Environ Microbiol 57:678-685

60. Liu EK, He WQ, Yan CR (2014) 'White revolution' to 'white pollution'agricultural plastic film mulch in China. Environ Research Lett 9:091001

61. Lobelle D, Cunliffe M (2011) Early microbial biofilm formation on marine plastic debris. Mar Pollut Bull 62:197-200

62. Lucas N, Bienaime C, Belloy C, Queneudec M, Silvestre F, Nava-Saucedo JE (2008) Polymer biodegradation: mechanisms and estimation techniques a review. Chemosphere 73:429-442

63. Lwanga EH, Thapa B, Yang X, Gertsen H, Salánki T, Geissen V, Garbeva P (2018) Decay of low-density polyethylene by bacteria extracted from earthworm's guts: a potential for soil restoration. Sci Total Environ 624:753-757

64. Manzur A, Limón-González M, Favela-Torres E (2004) Biodegradation of physicochemically treated LDPE by a consortium of filamentous fungi. J Appl Polym Sci 92:265-271

65. Matsubara M, Suzuki J, Deguchi T, Miura M, Kitaoka Y (1996) Characterization of manganese peroxidases from the hyperlignolytic fungus IZU-154. Appl Environ Microbiol 62:4066-4072

66. Das MP, Kumar S (2014) Microbial deterioration of low density polyethylene by Aspergillus and Fusarium sp. Int J ChemTech Res 6:299-305

67. Mishra IG, Sasidharan S, Tiwari S (2014) Aspergillus candidus: a phytase producing fungi. Int J Curr Sci 12:1-7

68. Mochizuki M, Hayashi T, Nakayama K, Masuda T (1999) Studies on biodegradable poly (hexane-6-lactone) fibers. Part 2. Environmental degradation (technical report). Pure Appl Chem 71:2177-2188

69. Mukherjee S, Roy Chowdhuri U, Kundu PP (2016) Bio-degradation of polyethylene waste by simultaneous use of two bacteria, Bacillus licheniformis for production of bio-surfactant and Lysinibacillus fusiformis for biodegradation. RSC Adv 6:2982-2992

70. Mukherjee S, Kundu PP (2014) Alkaline fungal degradation of oxidized polyethylene in black liquor: studies on the effect of lignin peroxidases and manganese peroxidases. J Appl Polym Sci 131:40738

71. MumtazT, Khan MR, Hassan MA (2010) Study of environmental biodegradation of LDPE films in soil using optical and scanning electron microscopy. Micron 41:430-438

72. North EJ, Halden RU (2013) Plastics and environmental health: the road ahead. Rev Environ Health 28:1-8

73. Novotný Č, Malachova K, Adamusc G, Kwiecień M, Lotti N, Soccio M, Verney V, Fava F (2018) Deterioration of irradiation/high-temperature pretreated, linear low-density polyethylene (LLDPE) by Bacillus amyloliquefaciens. Int Biodeterior Biodegradation 132:259-267

74. Nowak B, Paja J, Drozd-Bratkowicz KM, Rymarz G (2011) Microorganisms participating in the biodegradation of modified polyethylene films in different soils under laboratory conditions. Int Biodeterior Biodegradation 65:757-767
75. Ojha N, Pradhan N, Singh S, Barla A, Shrivastava A, Khatua P, Rai V, Bose S (2017) Evaluation of HDPE and LDPE degradation by fungus, implemented by statistical optimization. Sci Rep 7:39515

76. Orhan Y, Büyükgüngör H (2000) Enhancement of biodegradability of disposable polyethylene in controlled biological soil. Int Biodeterior Biodegradation 45:49-55

77. Otake Y, Kobayashi T, Asabe H, Murakami N, Ono K (1995) Biodegradation of low density polyethylene, polystyrene, polyvinyl chloride, and urea formaldehyde resin buried under soil for over 32 years. J Appl Polym Sci 56:1789-1796

78. Ozdemir M, Floros JD (2004) Active food packaging technologies. Crit Rev Food Sci Nutr 44:185-193

79. Pegram JE, Andrady AL (1989) Outdoor weathering of selected polymeric materials under marine exposure conditions. Polym Degrad Stab 26:333-345

80. PlasticsEurope, plastics-the facts (2018) An analysis of European plastics production, demand and waste data. Plastics-Europe, Belgium

81. Pometto AL, Lee BT, Johnson KE (1992) Production of an extracellular polyethylene-degrading enzyme(s) by Streptomyces species. Appl Environ Microbiol 58:731-733

82. Raaman N, Rajitha N, Jayshree A, Jegadeesh R (2012) Biodegradation of plastic by Aspergillus spp. isolated from polythene polluted sites around Chennai. J Acad Ind Res 1:313-316

83. Raghavan D, Torma AE (1992) DSC and FTIR characterization of biodegradation of polyethylene. Polym Eng Sci 32:438-442

84. Rajandas H, Parimannan S, Sathasivam K, Ravichandran M, Su Yin L (2012) A novel FTIR-ATR spectroscopy based technique for the estimation of low density polyethylene biodegradation. Polym Test 31:1094-1099

85. Ren L, Men L, Zhang Z, Guan F, Tian J, Wang B, Wang J, Zhang Y, Zhang W (2019) Biodegradation of Polyethylene by Enterobacter sp D1 from the Guts of Wax Moth Galleria mellonella. Int J Environ Res Public Health 16:1941

86. Restrepo-Florez JM, Bassi A, Thompson MR (2014) Microbial degradation and deterioration of polyethylene-a review. Int Biodeterior Biodegradation 88:83-90

87. Ribitsch D, Acero EH, Przylucka A, Zitzenbacher S, Marold A, Gamerith C, Tscheließnig R, Jungbauer A, Rennhofer $\mathrm{H}$, Lichtenegger $\mathrm{H}$, Amenitsch H, Bonazza K, Kubicek CP, Druzhinina IS, Guebitz GM (2015) Enhanced cutinase-catalyzed hydrolysis of polyethylene terephthalate by covalent fusion to hydrophobins. Appl Environ Microbiol 81:3586-3592

88. Ribitsch D, Yebra AO, Zitzenbacher S, Wu J, Nowitsch S, Steinkellner G, Doliska A, Oberdorfer G, Gruber CC, Gruber K, Schwab H, Kleinschek KS, Acero EH, Guebitz GM (2013) Fusion of binding domains to Thermobifida cellulosilytica cutinase to tune sorption characteristics and enhancing pet hydrolysis. Biomacromology 14:1769-1776

89. Rojo $F(2010)$ Enzymes for aerobic degradation of alkanes. SpringerVerlag, Berlin Heidelberg, In Handbook of Hydrocarbon and Lipid Microbiology

90. Rose RS, Richardson KH, Latvanen EJ, Hanson CA, Resmini M, Sanders IA (2020) Microbial degradation of plastic in aqueous solutions demonstrated by $\mathrm{CO}_{2}$ evolution and quantification. Int J Mol Sci 21:1176

91. Roy PK, Titus S, Surekha P, Tulsi E, Deshmukh C, Rajagopal C (2008) Degradation of abiotically aged LDPE films containing pro-oxidant by bacterial consortium. Polym Degrad Stab 93:1917-1922

92. Sammond DW, Yarbrough JM, Mansfield E, Bomble YJ, Hobdey SE, Decker SR, Taylor LE, Resch MG, Bozell JJ, Himmel ME, Vinzant TB, Crowley MF (2014) Predicting enzyme adsorption to lignin films by calculating enzyme surface hydrophobicity. J Biolog Chem 289:20960-20969

93. Santo M, Weitsman R, Sivan A (2013) The role of the copper-binding enzyme - laccase - in the biodegradation of polyethylene by the actinomycete Rhodococcus ruber. Int Biodeterior Biodegradation 84:204-210

94. Satlewal A, Soni R, Zaidi M, Shouche Y, Goel R (2008) Comparative biodegradation of HDPE and LDPE using an indigenously developed microbial consortium. J Microbiol Biotechnol 18:477-482

95. Secchi ER, Zarzur S (1999) Plastic debris ingested by a Blainville's beaked whale, Mesoplodon densirostris, washed ashore in Brazil. Aquat Mamm 25:21-24

96. Seneviratne G, Tennakoon N, Weerasekara M, Nandasena K (2006) Polyethylene biodegradation by a developed Penicillium-Bacillus biofilm. Curr Sci 90:20-21 
97. Sen SK, Raut S (2015) Microbial degradation of low density polyethylene (LDPE): a review. J Environ Chem Eng 3:462-473

98. Shah AA, Hasan F, Hameed A, Ahmed S (2008) Biological degradation of plastics: a comprehensive review. Biotechnol Adv 26:246-265

99. Shimao M (2001) Biodegradation of plastics. Curr Opin Biotechnol 12:242-247

100. Sivan A (2011) New perspectives in plastic biodegradation. Curr Opin Biotech 22:422-426

101. Sivan A, Szanto M, Pavlov V (2006) Biofilm development of the polyethylene degrading bacterium Rhodococcus ruber. Appl Microbiol Biotechnol 72:346-352

102. Sowmya HV, Ramalingappa Krishnappa M, Thippeswamy B (2014) Biodegradation of polyethylene by Bacillus cereus. Adv Polym Sci Technol Int J 4:28-32

103. Sowmya HV, Ramalingappa Krishnappa M, Thippeswamy B (2015) Degradation of polyethylene by Penicillium simplicissimum isolated from local dumpsite of shivamogga district. Environ Dev Sustain 17:731-745

104. Spear LB, Ainley DG, Ribic CA (1995) Incidence of plastic in seabirds from the tropical pacific, 1984-1991: relation with distribution of species, sex, age, season, year and body weight. Mar Environ Res 40:123-146

105. Sudhakar M, Doble M, Murthy PS, Venkatesan R (2008) Marine microbemediated biodegradation of low- and high-density polyethylenes. Int Biodeterior Biodegradation 61:203-213

106. Suhas Carrott PJM, Carrott MMLR (2007) Lignin - from natural adsorbent to activated carbon: a review. Bioresour Technol 98:2301-2312

107. Syranidou E, Karkanorachaki K, Amorotti F, Avgeropoulos A, Kolvenbach B, Zhou N, Fava F, Corvini PFX, Kalogerakis N (2019) Biodegradation of mixture of plasticfilms by tailored marine consortia. J Hazard Mater 375:33-42

108. Thankam Thomas R, Sandhyarani N (2013) Enhancement in the photocatalytic degradation of low density polyethylene- $\mathrm{TiO}_{2}$ nanocomposite films under solar irradiation. RSC Adv 3:14080-14087

109. Tharanathan RN (2003) Biodegradable films and composite coatings: past, present and future. Trends Food Sci Technol 14:71-82

110. Tribedi P, Sil AK (2013) Low-density polyethylene degradation by Pseudomonas sp. AKS2 biofilm. Environ Sci Pollut Res Int 20:4146-4153

111. Tokiwa Y, Calabia B, Ugwu C, Aiba S (2009) Biodegradability of plastics. Int J Mol Sci 10:3722-3742

112. Usha R, Sangeetha T, Palaniswamy M (2011) Screening of polyethylene degrading microorganisms from garbage soil. Libyan Agric Res Cent J Int 2:200-204

113. Volke-Sepúlveda T, Saucedo-Castañeda G, Gutiérrez-Rojas M, Manzur A, Favela-Torres E (2002) Thermally treated low density polyethylene biodegradation by Penicillium pinophilum and Aspergillus niger.J Appl Polym Sci 83:305-314

114. Webb HK, Arnott J, Crawford RJ, Ivanova EP (2013) Plastic degradation and its environmental implications with special reference to poly(ethylene terephthalate). Polymers 5:1-18

115. Weber C, Pusch S, Opatz T (2017) Polyethylene bio-degradation by caterpillars? Curr Biol 27:744-745
116. Wei R, Zimmermann W (2017) Microbial enzymes for the recycling of recalcitrant petroleum-based plastics: how far are we? Microb Biotechnol 10:1308-1322

117. Wilkes RA, Aristilde L (2017) Degradation and metabolism of synthetic plastics and associated products by Pseudomonas sp. Capabilities and challenges. J Appl Microbiol 123:582-593

118. Yakowitz H (1990) Incineration of municipal solid waste: scientific and technical evaluation of the state-of-the-art by an expert panel. Resour Conserv Recycl 4:241-251

119. Yamada-Onodera K, Mukumoto H, Katsuyaya Y, Saiganji A, Tani Y (2001) Degradation of polyethylene by a fungus, Penicillium simplicissimum YK. Polym Degrad Stab 72:323-327

120. Yang SS, Brandon AM, Andrew Flanagan JC, Yang J, Ning D, Cai SY, Fan $\mathrm{HQ}$, Wang ZY, Ren J, Benbow E, Ren NQ, Waymouth RM, Zhou J, Criddle CS, Wu WM (2018) Biodegradation of polystyrene wastes in yellow mealworms (larvae of Tenebrio molitor Linnaeus): factors affecting biodegradation rates and the ability of polystyrene-fed larvae to complete their life cycle. Chemosphere 191:979-989

121. Yang Y, Yang J, Wu W, Zhao J, Song Y, Gao L, Yang R, Jiang L (2015) Biodegradation and mineralization of polystyrene by plastic eating mealworms: part 1. Chemical and physical characterization and isotopic tests. Environ Sci Technol 49:12080-12086

122. Yang Y, Yang J, Wu W, Zhao J, Song Y, Gao L, Yang R, Jiang L (2015) Biodegradation and mineralization of polystyrene by plastic eating mealworms: part 2. Role of gut microorganisms. Environ Sci Technol 49:12087-12093

123. Yang J, Yang Y, Wu WM, Zhao J, Jiang L (2014) Evidence of polyethylene biodegradation by bacterial strains from the guts of plastic-eating waxworms. Environ Sci Technol 48:13776-13784

124. Yoon MG, Jeon HJ, Kim MN (2012) Biodegradation of polyethylene by a soil bacterium and AlkB cloned recombinant cell. J Bioremed Biodegrad 3:145

125. Zan L, Fa W, Wang S (2006) Novel photodegradable low-density polyethylene- $\mathrm{TiO}_{2}$ nanocomposite film. Environ Sci Technol 5:1681-1685

126. Zhao X, Li Z, Chen Y, Shi L, Zhu Y (2008) Enhancement of photocatalytic degradation of polyethylene plastic with $\mathrm{CuPc}$ modified $\mathrm{TiO}_{2}$ photocatalyst under solar light irradiation. Appl Surf Sci 254:1825-1829

127. Zheng Y, Yanful EK, Bassi AS (2005) A review of plastic waste biodegradation. Crit Rev Biotechnol 25:243-250

128. Zumstein MT, Schintlmeister A, Nelson TF, Baumgartner R, Woebken D, Wagner M, Kohler HPE, McNeill K, Sander M (2018) Biodegradation of synthetic polymers in soils: tracking carbon into $\mathrm{CO}_{2}$ and microbial biomass. Sci Adv 4:eaas9024

\section{Publisher's Note}

Springer Nature remains neutral with regard to jurisdictional claims in published maps and institutional affiliations.

\section{Submit your manuscript to a SpringerOpen ${ }^{\circ}$ journal and benefit from:}

- Convenient online submission

- Rigorous peer review

- Open access: articles freely available online

- High visibility within the field

- Retaining the copyright to your article

Submit your next manuscript at $\boldsymbol{\nabla}$ springeropen.com 